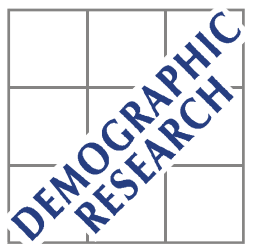

Demographic Research a free, expedited, online journal of peer-reviewed research and commentary in the population sciences published by the Max Planck Institute for Demographic Research Konrad-Zuse Str. 1, D-18057 Rostock · GERMANY www.demographic-research.org

DEMOGRAPHIC RESEARCH

VOLUME 13, ARTICLE 23, PAGES 573-596

PUBLISHED 07 DECEMBER 2005

http://www.demographic-research.org/Volumes/Vol13/23/

DOI: 10.4054/DemRes.2005.13.23

Descriptive Findings

Modelling regional variation of first-time births in Denmark 1980-1994 by an age-period-cohort model

Lau Caspar Thygesen

Lisbeth B. Knudsen

Niels Keiding

(C) 2005 Max-Planck-Gesellschaft. 


\section{Table of Contents}

1 Introduction $\quad 574$

2 Data $\quad 575$

3 Methods $\quad 579$

$4 \quad$ Results $\quad 580$

4.1 Modelling the effects of age, period and cohort 581

$\begin{array}{lll}4.2 & \text { Regional variation } & 584\end{array}$

$\begin{array}{lll}5 & \text { Discussion } & 589\end{array}$

6 Conclusion $\quad 593$

References $\quad 594$ 


\title{
Modelling regional variation of first-time births in Denmark 1980-1994 by an age-period-cohort model
}

\author{
Lau Caspar Thygesen ${ }^{1}$ \\ Lisbeth B. Knudsen ${ }^{2}$ \\ Niels Keiding ${ }^{3}$
}

\begin{abstract}
Despite the fact that Denmark is a small country, historically there have been fairly consistent regional differences in fertility rates. We apply the statistical age-periodcohort model to include the effect of these three time-related factors to concisely illuminate the regional differences in first-time births in Denmark. From the Fertility of Women and Couples Dataset we obtain data on the number of births by nulliparous women by year (1980-1994), age (15-45) and county of residence. We show that the APC-model describes the fertility rates of nulliparous women satisfactorily. To identify the regional variation an interaction parameter between age and county is necessary, and this provides a surprisingly good description, suggesting that the county-specific age-distributions of first-time fertility rates differ. Our results are in general agreement with the 'moral geography' concepts of Tonboe (2001).
\end{abstract}

\footnotetext{
${ }^{1}$ Research Assistant, Centre for Alcohol Research, National Institute of Public Health, Copenhagen, Denmark. Correspondence to: Lau Caspar Thygesen, Centre for Alcohol Research, National Institute of Public Health, Øster Farimagsgade 5, DK-1399 Copenhagen K, Denmark, teleph +4539207777, fax +45 39464002 / +45 39208010. E-mail: lct@niph.dk

${ }^{2}$ Associate Professor, Department of Social Studies and Organization, Aalborg University, Denmark

${ }^{3}$ Professor, Department of Biostatistics, Institute of Public Health, University of Copenhagen, Denmark
} 


\section{Introduction}

The fertility pattern in Denmark changed dramatically during the last part of the $20^{\text {th }}$ century. The total fertility rate (TFR) was relatively high after the Second World War (TFR=3.02 children per woman in 1946) while it decreased steeply at the end of the 1960s and less strongly through the 1970s until 1983 when the minimum was reached ( $T F R=1.38$ children per woman). From that point on the TFR increased to 1.80 children per woman at the start of the 1990s.

In the period investigated in this study (1980-1994), the development of TFR conceals different trends for specific age groups. With few exceptions the age-specific fertility rates for women below the age of 26 constantly decreased during the whole period, while the decline in fertility rates for women in their late twenties and above reversed in 1981. The fertility rates for these women increased throughout the rest of the study period. Throughout the period investigated in this study, the average maternal age at the birth of the first child steadily increased. These general patterns in Denmark might indicate that after 1983 women give birth to an increasing number of children but that they are still older when giving birth for the first time (Knudsen 1993).

Regarding the fertility pattern, the observed decline in fertility since the end of the 1960s has been shown to be running more or less in parallel in the sixteen counties of Denmark, indicating the existence of fairly stable regional differences in spite of the relatively small size of the country (Pedersen 1988). An analysis of both women's and men's age at onset of fertility, lifetime fertility and the proportion of childless at given ages demonstrated the existence of regional (county) differences in the fertility patterns of both genders in Denmark in the period from 1980 to 1993 (Statistics Denmark 1997). These regional fertility differences were in accordance with the pattern based on data from the census of 1901, demonstrated by Johansen (2002): The lowest average number of children was seen among civil servants in towns (4.1) and the highest average (6.4) among rural estate owners. Comparing the fertility among 35 year old women (in 1993), the analysis revealed that those living in the western, less urbanised part of Denmark had given birth to close to two children on average, while women living in the metropolitan area had had fewer children, namely 1.0-1.6 children. It should be noted, though, that this analysis was based on cohort measures of fertility for each woman but only one record of the place of residence - that at the beginning of the year where they turned 35. In addition, the mean maternal age at first birth was higher in the metropolitan area (28.2) than in the less urbanized counties, in which the lowest mean age at first birth was 25.1 .

The apparently persistent regional fertility differences indicate the existence of an underlying set of characteristics influencing the individuals' fertility and familiy formation behaviour. Regional consistency regarding attitudes and behaviour has been 
noted in Denmark for aspects of human life other than fertility. As an attempt to study 'the geography of morality', Tonboe (2001) has suggested a grouping of the counties in Denmark based on the Danish section of the European Value Study, based on a large number of characteristics: the Capital area, the Urbanised provincial part of the country, the Close periphery and the Distant periphery.

In the year 1990, which is two-thirds through the study period, the variation between the counties in Denmark is large when analysing TFR as well as age-specific fertility rates. TFR ranged from 1.95 children per woman (Viborg county in the west) to 1.30 children per woman (Frederiksberg in the eastern metropolitan area) and for women younger than 20 the fertility rates varied between 7.0 per 1,000 women (Ringkøbing in the west) and 16.8 per 1,000 women in Copenhagen (Statistics Denmark 1992).

To our knowledge, the variation in fertility between counties has not previously been analysed for nulliparous women, which is the focus of this investigation. We will analyse the fertility rates of nulliparous women in order to shed light on one dimension of the phenomenon that the age at which women give birth for the first time is still increasing and that there are marked and consistent regional differences in Denmark. The statistical age-period-cohort model will be applied to analyse the effect of age, calendar year and birth cohort simultaneously, with the obvious but novel extension of a regression term for the regional variation in the model. However, when several timerelated factors are in play in complex combinations, it is difficult to discern clear patterns in the temporal variation in fertility rates. Statistical modelling techniques could hopefully separate the effects of age, period and cohort and so concisely illuminate the regional differences in first-time births in Denmark 1980-1994. To further elucidate these differences we will apply the APC-model to the abovementioned county grouping suggested by Tonboe (2001).

\section{Data}

The analysis uses aggregated data extracted from the Fertility of Women and Couples Dataset (FWCD), which is primarily based on the Fertility Database (Knudsen 1998). As the information as to whether the women give birth was originally retrieved from the official Medical Register of Birth and Death Statistics, this information has a high validity (Eurostat/Statistics Denmark 1995). In short, the FWCD contains information for all women of fertile age (13-49) in Denmark each year 1980-1994 (Knudsen and Murphy 1999). For each woman (and her co-resident male partner) the fertility at a given age can be described by, for instance, the number of live as well as stillborn 
children and the age at the onset of fertility. For the present analysis only the information about women is used.

The specific dataset for the analysis was created as follows: for each woman who gave birth for the first time in the period 1980-1994 inclusive, information about the year of the delivery as well as the woman's age (in completed years) and her county of residence at the beginning ( 1 January) of the year in which the child was born, was retrieved.

In the calculation of the annual fertility rates for nulliparous women in each of the 15 years for the 37 age groups, the number of women likely to give birth for the first time is approximated by the average number of nulliparous women $1^{\text {st }}$ of January the same and the following year. For the last year in the study period (1994), the number of women likely to give birth is approximated by the number of nulliparous women on $1^{\text {st }}$ January 1994.

For delivering women, the age taken is that of the woman at the time of giving birth in full years. We have data for the age groups from 13-49 $(\mathrm{A}=37)$ indexed a $(\mathrm{a}=13, \ldots, 49)$. Period refers to the calendar year in which the women give birth to the first child. We have data for the period 1980-1994 inclusive $(\mathrm{P}=15)$ and indexed $\mathrm{p}$ $(\mathrm{p}=1980, \ldots, 1994)$. In the Fertility Database, from which the data were originally retrieved, the information about childbirth is considered complete for all women born since 1945, due to the characteristics of the Civil Population Registration and the medical registration of births, (the latter was established in 1973). This is further discussed by Knudsen (Knudsen 1993).

Table 1 shows the number of nulliparous delivering women for each age and for each year in our dataset. 
Table 1: Number of nulliparous women giving birth by age and calendar year

\begin{tabular}{|c|c|c|c|}
\hline Age & $\begin{array}{l}\text { Number of nulliparous } \\
\text { delivering women }\end{array}$ & Year & $\begin{array}{l}\text { Number of nulliparous } \\
\text { delivering women }\end{array}$ \\
\hline 13 & 6 & 1980 & 25790 \\
\hline 14 & 47 & 1981 & 23884 \\
\hline 15 & 276 & 1982 & 23512 \\
\hline 16 & 1168 & 1983 & 22895 \\
\hline 17 & 3471 & 1984 & 23587 \\
\hline 18 & 7484 & 1985 & 24408 \\
\hline 19 & 14093 & 1986 & 25315 \\
\hline 20 & 20153 & 1987 & 25779 \\
\hline 21 & 25971 & 1988 & 26890 \\
\hline 22 & 30497 & 1989 & 28074 \\
\hline 23 & 34192 & 1990 & 28887 \\
\hline 24 & 37490 & 1991 & 29032 \\
\hline 25 & 39424 & 1992 & 29536 \\
\hline 26 & 37458 & 1993 & 28905 \\
\hline 27 & 32961 & 1994 & 29538 \\
\hline 28 & 27223 & & \\
\hline 29 & 21944 & & \\
\hline 30 & 16721 & & \\
\hline 31 & 12622 & & \\
\hline 32 & 8965 & & \\
\hline 33 & 6811 & & \\
\hline 34 & 5043 & & \\
\hline 35 & 3773 & & \\
\hline 36 & 2742 & & \\
\hline 37 & 1942 & & \\
\hline 38 & 1399 & & \\
\hline 39 & 920 & & \\
\hline 40 & 558 & & \\
\hline 41 & 354 & & \\
\hline 42 & 202 & & \\
\hline 43 & 107 & & \\
\hline 44 & 55 & & \\
\hline 45 & 13 & & \\
\hline 46 & 9 & & \\
\hline 47 & 2 & & \\
\hline 48 & 1 & & \\
\hline 49 & 0 & & \\
\hline
\end{tabular}


It can be seen from the table that there are very few nulliparous delivering women in both the youngest and the oldest age groups. Therefore, the youngest (13-14) and oldest (46+) age groups are excluded from the following investigation, which consequently includes 31 age groups indexed $a(a=15, \ldots, 45)$.

Cohort refers to the year in which the women were born and which we have estimated by the relation cohort $=$ period - age. In our dataset the oldest cohort is women aged 45 in 1980 (the 1935 birth cohort) and the youngest cohort is women aged 15 in 1994 (the 1979 birth cohort). This estimation of the cohort membership means it was not possible to infer the precise cohort for each woman (Arbyn 2002).

The data also include information about the county of residence as of $1^{\text {st }}$ January in the year of giving birth for each of the nulliparous women. Denmark is a relatively small country with a total area of 43,095 square kilometres and a little more than 5.2 million inhabitants. Administratively, the country is divided into 14 counties and the municipalities of Copenhagen (the Capital) and Frederiksberg, of which the latter two have a status as both counties and municipalities. The Metropolitan area dominates the eastern part of the country while the western part (the Jutland peninsula) is generally more sparsely populated, although the $2^{\text {nd }}$ and $4^{\text {th }}$ largest cities are situated in Jutland. Regional analyses most often use the county as the unit for analysis or grouping into east and west Denmark, see Figure 1 and Table 2.

\section{Figure 1: Map of the counties of Denmark}

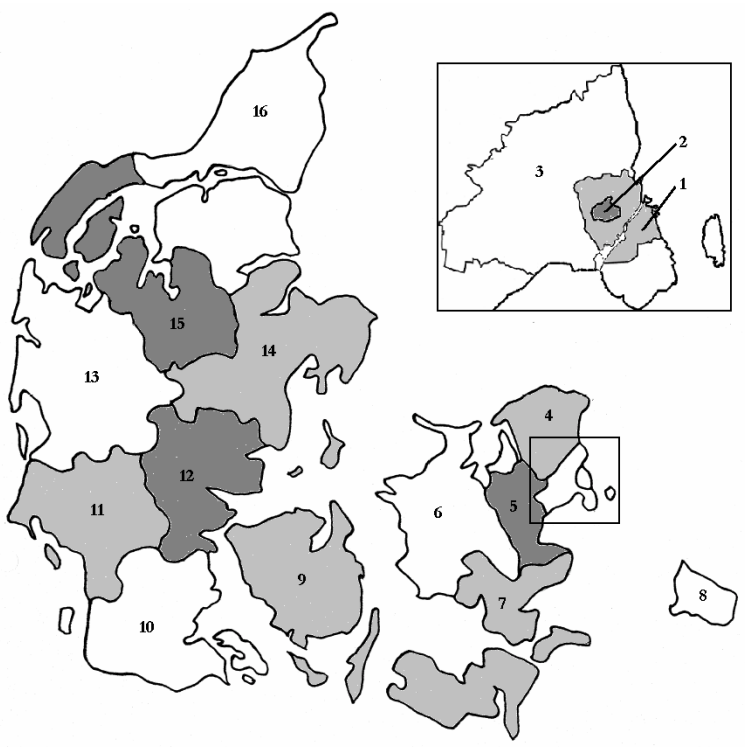


Table 2: $\quad$ Counties in Denmark

\begin{tabular}{ll}
\hline 1. Copenhagen Municipality* & 9. Fyn County \\
2. Frederiksberg Municipality* & 10. South Jutland County \\
3. Copenhagen County & 11. Ribe County \\
4. Frederiksborg County & 12. Vejle County \\
5. Roskilde County & 13. Ringkøbing County \\
6. Western Zealand County & 14. Aarhus County \\
7. Storstrøm County & 15. Viborg County \\
8. Bornholm County & 16. North Jutland County \\
${ }^{*}$ The municipalities of Copenhagen and Frederiksberg have a special status and are regarded both as \\
\multicolumn{2}{l}{ municipalities and as counties. }
\end{tabular}

The municipalities of Copenhagen and Frederiksberg and Copenhagen county are almost completely urbanised as expressed by the percentage of citizens living in urban areas with at least 200 residents, while Viborg, Storstrøm and Bornholm counties have the lowest percentage of citizens living in urban areas of at least that size. In Copenhagen and Aarhus counties the number of citizens are highest, while Bornholm county, Frederiksberg municipality and Ribe county have fewest citizens. The information about county of residence will be included in the analyses to estimate the effect of county on the first-birth fertility rate in the period.

\section{Methods}

The fertility rate of the nulliparous women will be analysed according to the three timescales defined above (age of the nulliparous woman giving birth, the period of giving birth and the birth cohort of the woman giving birth) and the county of residence.

For the initial analysis we disregard county of residence; then trends in agespecific fertility rates are related either to calendar time (period), to cohort, i.e. year of birth, or to both. To allow for simultaneous effects of period and cohort, an age-periodcohort model was applied to the Danish fertility data. Denote the first-child fertility rate at period $\mathrm{p}$ and age a (and hence cohort $\mathrm{c}=\mathrm{p}-\mathrm{a}$ ) by $\lambda_{a p}$. The age-period-cohort model postulates the additive decomposition

$$
\log \left(\lambda_{\mathrm{ap}}\right)=\alpha_{\mathrm{a}}+\beta_{\mathrm{p}}+\gamma_{\mathrm{c}}
$$

Because of the exact linear dependency period $=$ age + cohort (Holford 1992), there is an important and well-known identification problem in the age-period-cohort model. This means that it is not possible to separate the effects of period and age + 
cohort by simply regressing fertility rates on these variables. This problem has been thoroughly discussed (Clayton and Schifflers 1987a,b, Robertson and Boyle 1998a,b) and one possible approach is to introduce a drift parameter $\varepsilon$ (a log-linear trend parameter), which is identifiable but may be ascribed neither to period nor to cohort effects, and constraining two calendar periods and two cohorts to be zero, which was done in the present analysis:

$$
\log \left(\lambda_{\mathrm{ap}}\right)=\alpha_{\mathrm{a}}+\beta_{\mathrm{p}}+\gamma_{\mathrm{c}}+\varepsilon\left(\mathrm{p}-\mathrm{p}_{0}\right)
$$

where $\mathrm{p}$ and $\mathrm{c}$ are values of period and cohort so that $\beta_{1982}=\beta_{1992}=\gamma_{1945}=\gamma_{1967}=0$ and $\mathrm{p}_{0}$ is a baseline period $\left(\mathrm{p}_{0}=1980\right)$. The model was fitted using SAS PROC GENMOD with Poisson error distribution and log link (SAS Institute Inc. 1999).

When fitting data of an enormous sample size as in this study, almost any significance tests of specific parameters or of whole models will be highly significant. But a statistically significant effect need not be important in a practical sense. With huge samples, it is crucial to focus on estimation rather than hypothesis testing, because simpler models are easier to summarize. The primary method for assessing the adequacy of the models estimated will be to compare the estimated fertility rates from the model with the observed fertility rates. This will give an impression of the models' predictive abilities. The secondary method will be to compare the deviance of the model with the degrees of freedom. If these two numbers approach each other the fit of the model is assumed to be satisfactory (Arbyn 2002).

The variation by county will be modelled within the same framework. One obvious solution is to introduce the county effect into the APC-model:

$$
\log \left(\lambda_{\text {ap }, \text { county }}\right)=\alpha_{\mathrm{a}}+\beta_{\mathrm{p}}+\gamma_{\mathrm{c}}+\varepsilon\left(\mathrm{p}-\mathrm{p}_{0}\right)+\delta_{\text {county }}
$$

This model has the same problem of identification of age, period and cohort as described above, but the interpretation of the county estimates could be taken as the relative rate (antilog of the estimates) compared to a reference county. As we shall see, more elaborate models allowing interaction will be necessary.

\section{Results}

In this section we will present the results from the modelling of the simultaneous effects of age, period and cohort and additionally the effect of the 16 counties. 


\subsection{Modelling the effects of age, period and cohort}

We start with an age-period model: $\log \left(\lambda_{\mathrm{ap}}\right)=\alpha_{\mathrm{a}}+\beta_{\mathrm{p}}$. The age-specific log-fertility curves plotted against period should be parallel, if the AP-model fitted well. As seen in Figure 2, where the solid lines are observed rates and dotted lines are the expected rates under the AP-model, the model does not give a good description of the data because the effect of period differs between specific age groups. The age-period model predicts that the development for every age group is a decrease until 1983 and thereafter a slight increase of the log-fertility rates for the rest of the period. This prediction does not fit well for the youngest age groups where the model does not capture the decreasing trend through the period, and for the older age groups the model gives a completely erroneous description of the data.

Figure 2: Age-period model of first time fertility for 20, 25 and 30 year-old women in Denmark 1980-1994

Dotted lines are expected rates and solid lines are observed rates

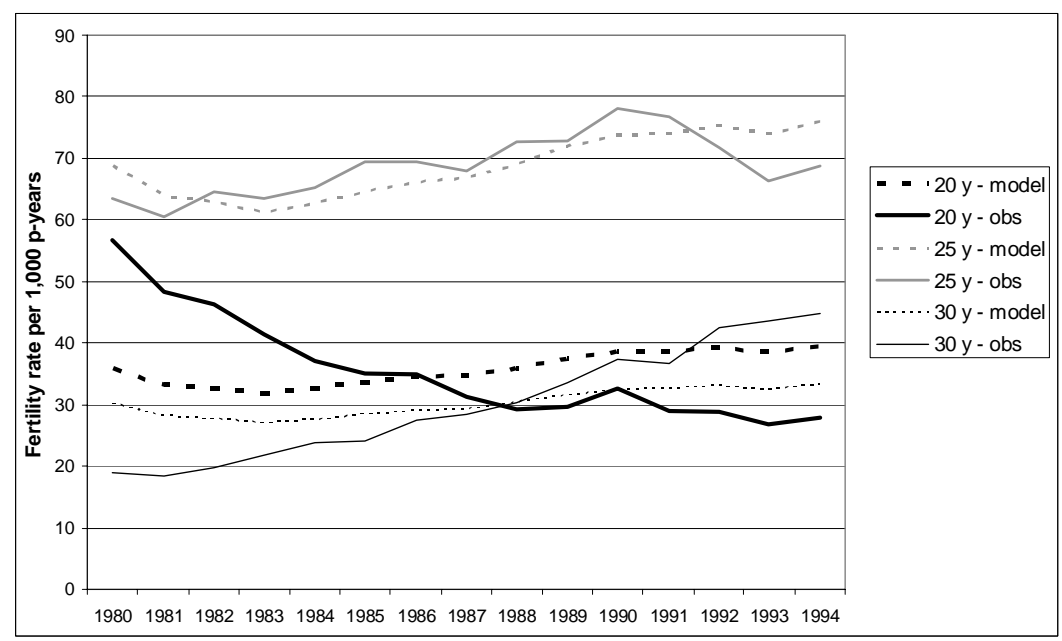

Instead of modelling the age-period model, an alternative model could be the agecohort model: $\log \left(\lambda_{\mathrm{ap}}\right)=\alpha_{\mathrm{a}}+\gamma_{\mathrm{c}}$. The fit of this model is shown in Figure 3, which shows that this model captures the development for the oldest age group (30 years of age) better than the age-period model, though still not quite satisfactorily. 
Figure 3: Age-cohort model of first time fertility for 20, 25 and 30 year-old women in Denmark 1980-1994

Dotted lines are expected rates and solid lines are observed rates

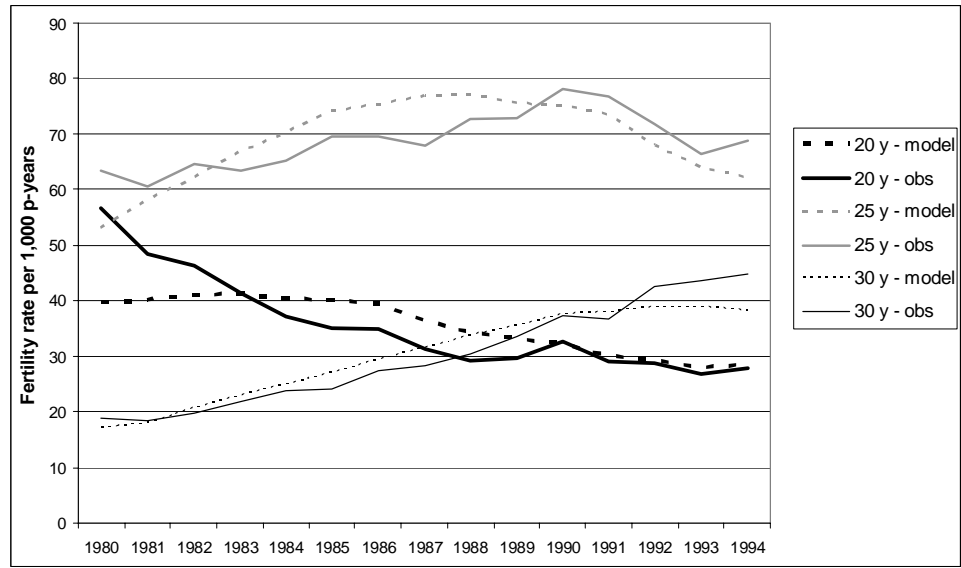

The age-period-cohort model (1) allows for non-parallel age specific fertility curves as a function of drift, cohort or period. The observed and expected plots for this model can be found in Figure 4.

Figure 4: Age-period-cohort model of first time fertility for 20, 25 and 30 yearold women in Denmark 1980-1994

Dotted lines are expected rates and solid lines are observed rates

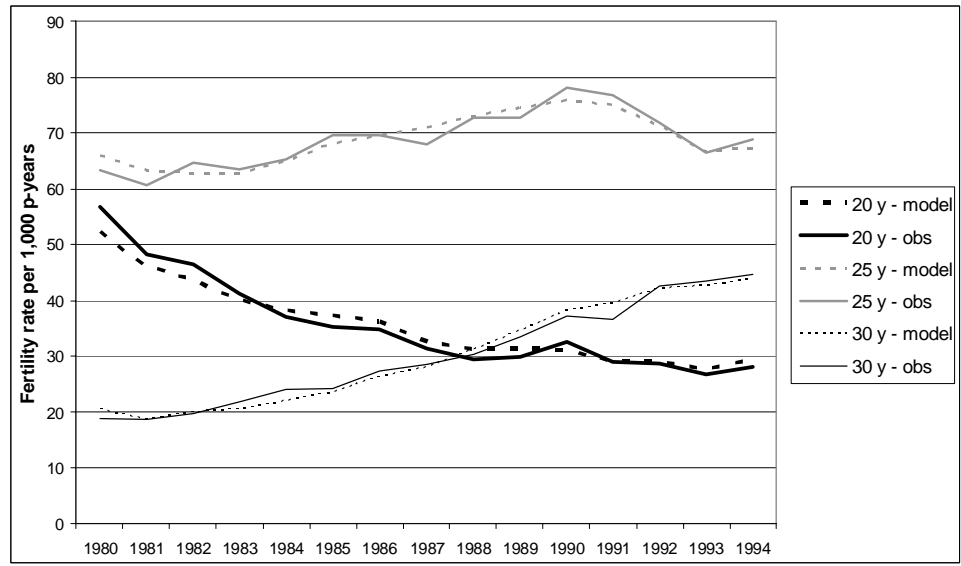


This model seems to fit the data much better than the previous models presented. The model allows for the fact that the slopes of the different age groups are not identical so that it decreases for the younger groups and increases for the older.

The estimated fertility rates under the age-period-cohort model are represented in Figure 5.

\section{Figure 5: Estimated fertility rates under the age-period-cohort model}

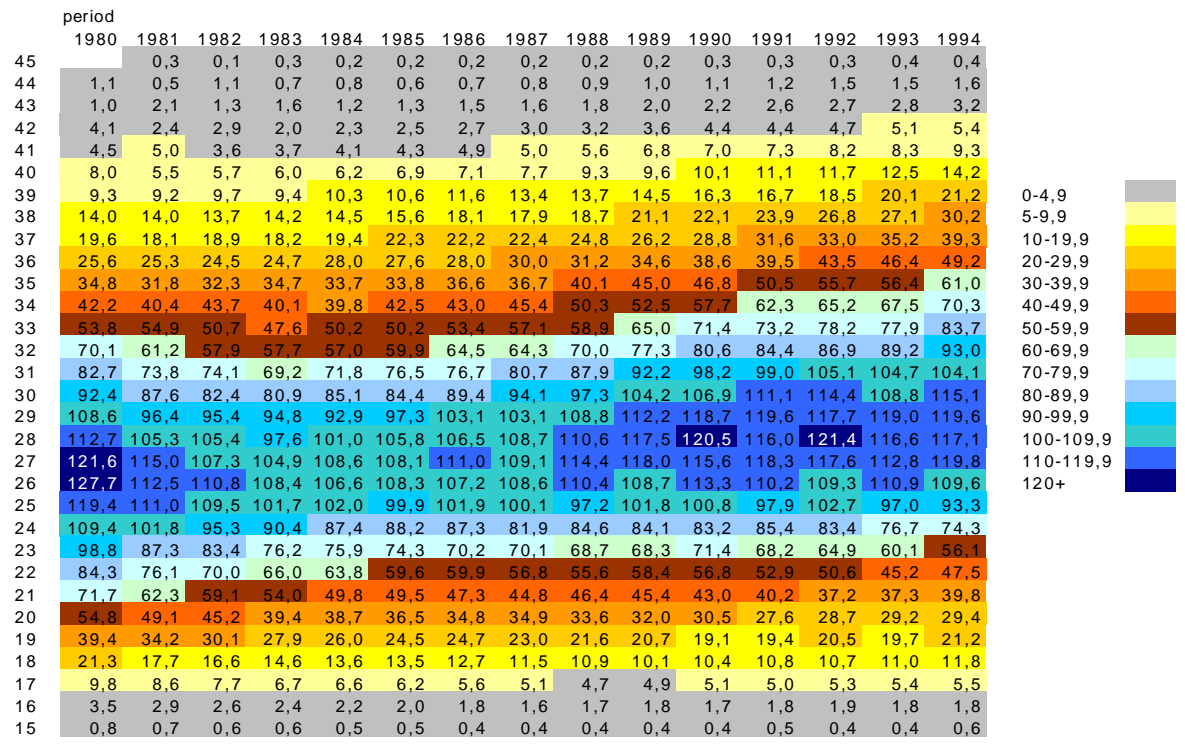

To compare the models introduced above, a deviance analysis has been carried out. The results of this analysis are shown in Figure 6. The figure shows that the full ageperiod-cohort model gives the best fit of the data compared with the age-period and age-cohort models ( $\mathrm{D} / \mathrm{df}=3.2358)$, which was also obvious from the above.

The age-period-cohort model could be understood as an advanced standardisation with respect to the three interrelated time factors. We will use this standardisation when we examine the regional variation of first time fertility in Denmark 1980-1994. 
Figure 6: Model selection by deviance analysis of the fitted models

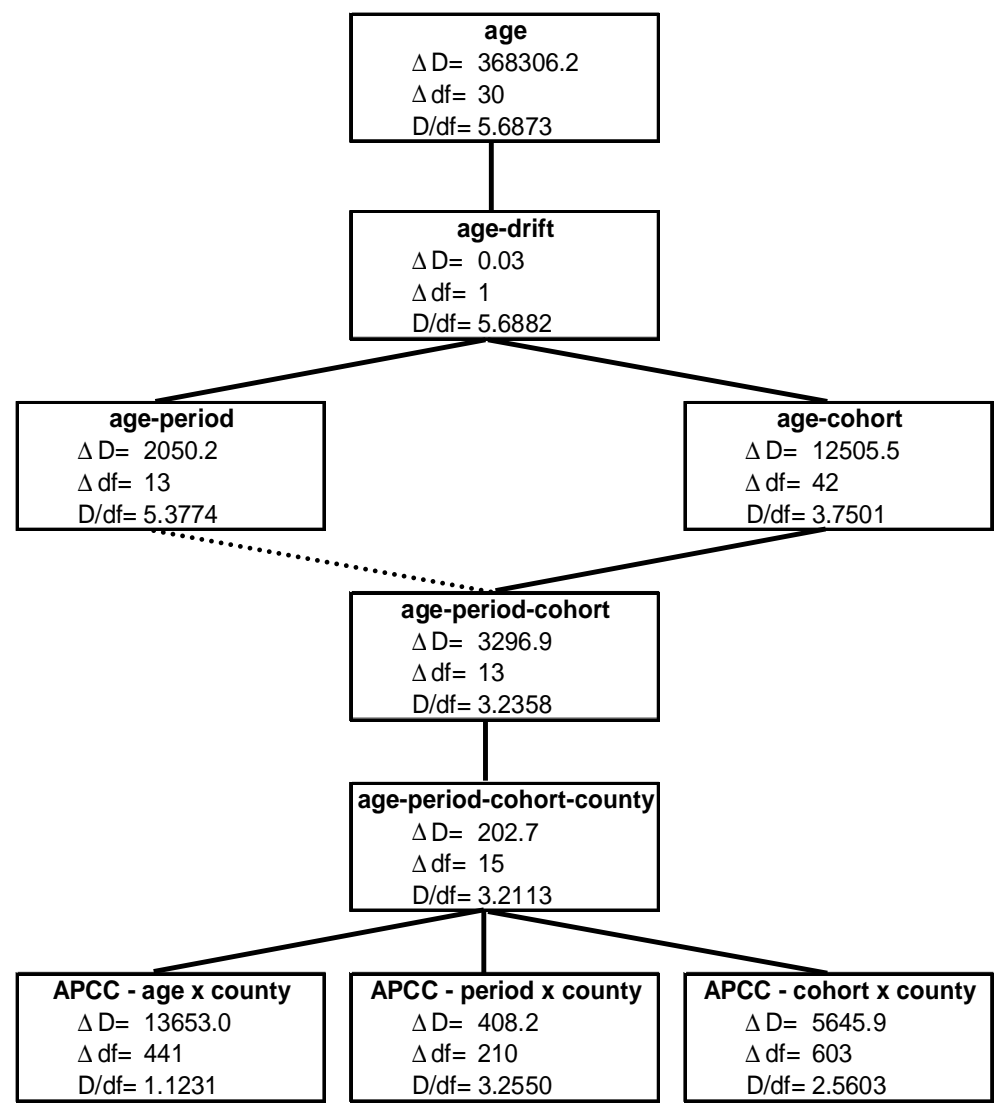

\subsection{Regional variation}

The basis for the analyses will be the full APC-model with an additional parameter for the counties.

When the fertility rates estimated for each county by the model are compared with the observed fertility rates the model does not fit well, as exemplified in Figures 7 and 8. 
Figure 7: Age-period-cohort-county model of first time fertility for 25 year- old women living in Ringkøbing and Fyn counties 1980-1994

Dotted lines are expected rates and solid lines are observed rates

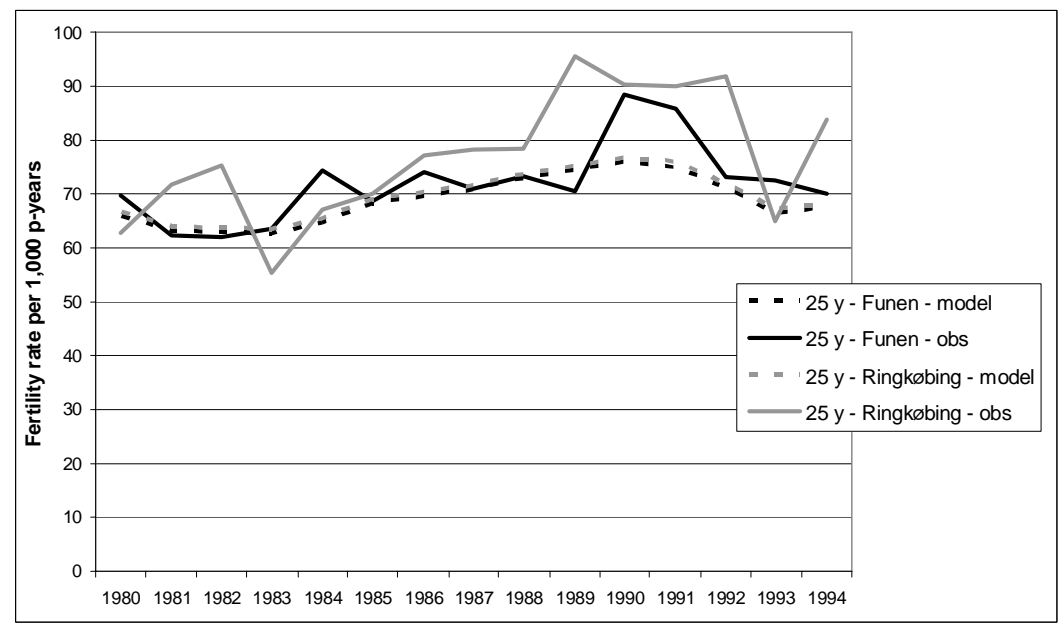

Figure 8: Age-period-cohort-county model of first time fertility for 20, 25 and 30 year-old women living in Copenhagen Municipality 1980-1994 Dotted lines are expected rates and solid lines are observed rates

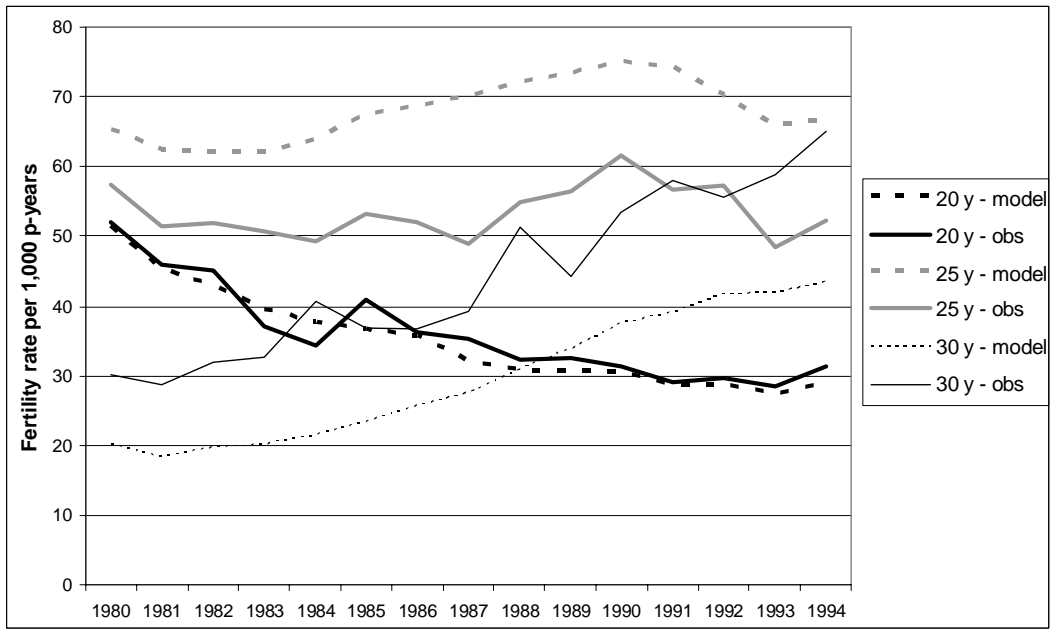


The figures illustrate that the fit of the model is not striking. Although the deviance has increased slightly compared with the APC-model (see Figure 6), the fit is not quite satisfactory for some of the counties (e.g. Ringkøbing and Fyn counties for 25 year-old women). For Copenhagen Municipality the estimates of the model fit well for the young age group (20), but are too high for the 25 year-old women and far too low for the 30 year-olds. This suggests that the trend in Copenhagen Municipality differs from the general trend in Denmark.

These figures illustrate a phenomenon where the age-distribution of first time fertility varies across Denmark, i.e. that the age-specific fertility rates are heterogeneous for different counties. Therefore, a model with an interaction between the specific counties and age is suggested, which might produce a better fit.

$$
\log \left(\lambda_{\text {ap }, \text { county }}\right)=\alpha_{\mathrm{a}}+\beta_{\mathrm{p}}+\gamma_{\mathrm{c}}+\varepsilon\left(\mathrm{p}-\mathrm{p}_{0}\right)+\delta_{\text {county }}+\zeta_{\mathrm{a}, \text { county }}
$$

The convincingly good fit of this model is supported by Figure 6 where the D/dfstatistics approach unity compared to the models with interactions between county and period and county and cohort. Figures 9 and 10 further support this conclusion by showing the fitted rates and the observed rates for the municipality of Copenhagen and Ribe county.

Figure 9: Age-period-cohort-county, age-county-interaction model of first time fertility for 20, 25 and 30 year-old women living in Copenhagen Municipality 1980-1994

Dotted lines are expected rates and solid lines are observed rates

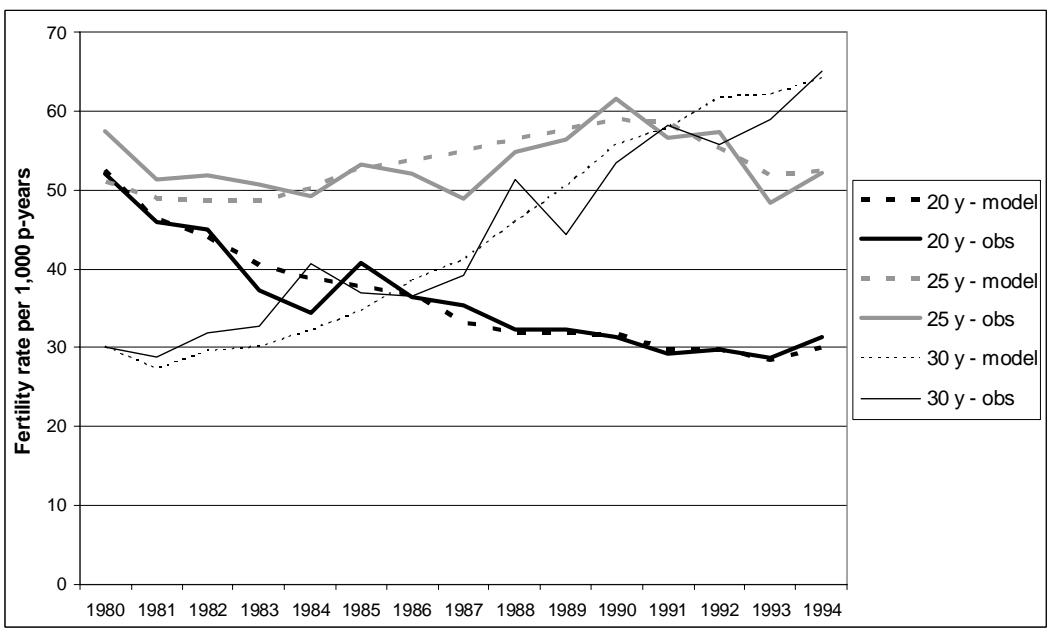


Figure 10: Age-period-cohort-county, age-county-interaction model of first time fertility for 20, 25 and 30 year-old women, living in Ribe county 1980-1994

Dotted lines are expected rates and solid lines are observed rates

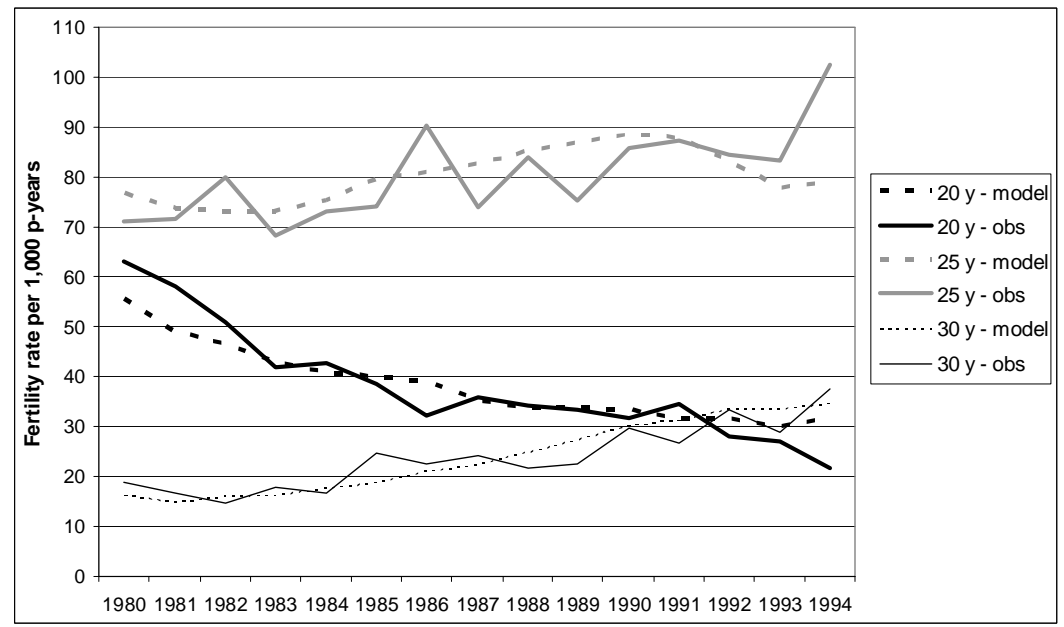

This model seems to capture the fairly divergent fertility rates of the counties strikingly well: The model fits the fertility rates of Copenhagen much better than the model without the interaction parameters and also fits the rates of Ribe County satisfactorily.

The different age-specific fertility rates of the counties with lower rates for younger women and higher rates for women at the upper end of the fertile age-span in the municipalities of Copenhagen and Frederiksberg are captured with the model, while the rates of the more rural counties are also captured satisfactorily.

The model specifies different age-structures for the individual counties, which is illustrated in Figures 11 and 12 where the age-specific rates estimated by the model are illustrated for the 14 counties and 2 municipalities. 
Figure 11: Estimated age-specific first time fertility rates in age-period-cohortcounty, age-county-interaction model for Eastern Denmark 1980-1994

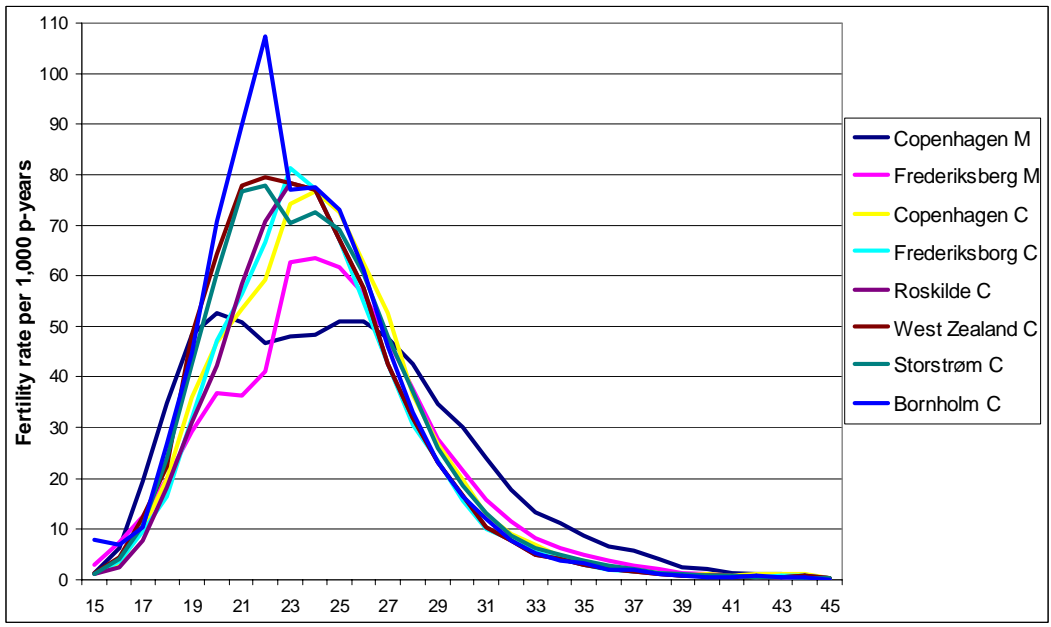

Figure 12: Estimated age-specific first time fertility rates in age-period-cohortcounty, age-county-interaction model for Western Denmark 19801994

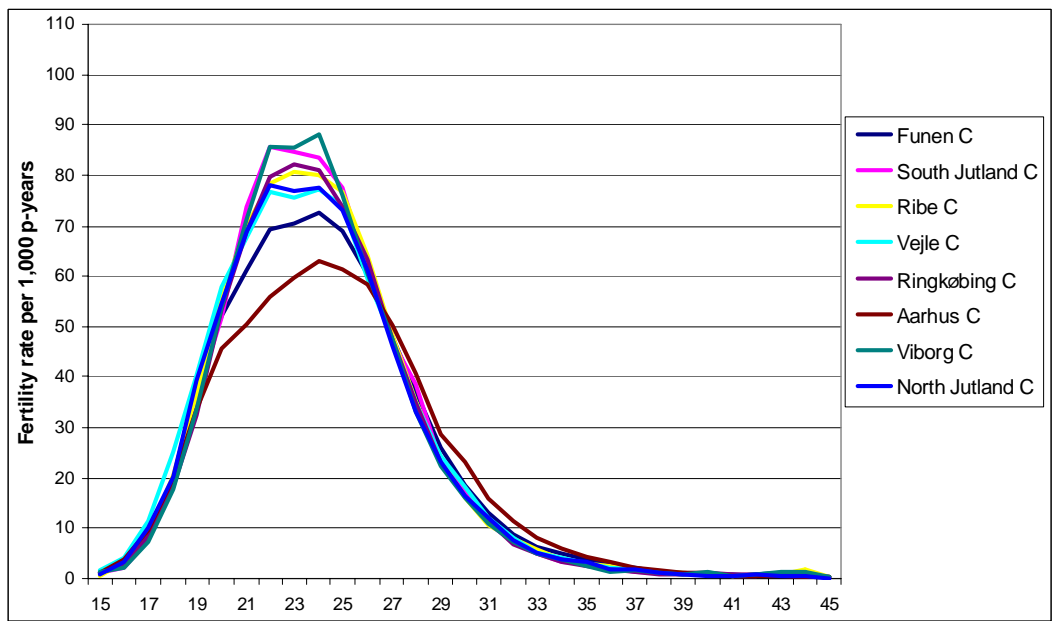


The two figures complement the previous findings by showing that the fertility rates of the younger women are especially low in Frederiksberg Municipality, but also in the counties of Aarhus, Copenhagen and to some extent Fyn. The fertility rates of younger women are higher in the counties of Viborg, South Jutland, Bornholm, West Zealand and Storstrøm. Copenhagen Municipality differs by relative high fertility rates for women below the age of 20, low rates for women between 21 and 27 and higher rates for women above 28 . For the other counties the differences in fertility rates for women aged 25 and above do not show great differences between the counties. It should be emphasized that the fertility rates are adjusted for both the effect of period and cohort, and so the age-specific fertility rates could be interpreted as standardised rates. Overall, we have demonstrated the existence of a regional variation in the onset of fertility, which will be further examined in the following sections.

\section{Discussion}

Studies of national differences in reproductive patterns have often focused on differences in family policies, either by aiming at studying the effect of specific policy measures (Gauthier and Hatzius 1997, Kaufmann 2002) or by relating aggregated fertility measures to the policy regimes, e.g. the various welfare state regimes (Gauthier 1996, Hantrais and Letablier 1996, Neyer 2003). Other research has pointed to the relationship between fertility behaviour and underlying cultural factors and individuals' value orientations (e.g., Surkyn and Lestaghe 2004). The situation is somewhat different when analysing the regional variation in fertility behaviour, at least in a country like Denmark, where the overall policy measures are the same and only minor policy differences exist between the regions.

There are relatively few studies of the regional variation in fertility behaviour and/or family formation in Denmark, although a number of aggregate regional measures are included in the annually published vital statistics, thus facilitating a 'crude' monitoring of the development. However, the available findings have been concordant and demonstrate actual regional differences as regards both earlier onset of childbearing, higher fertility, larger families (Statistics Denmark 1997, Statistics Denmark 2000) and lower rate of induced abortion (Knudsen 2000) in the western, less urbanised parts of the country compared to the rest of the country, especially the Metropolitan area including Copenhagen.

Similar differences were found 100 years ago. As touched upon in the introductory part of this article, the Danish census from 1901 included a lifetime parity of women approximated by the number of children in marriages that had lasted at least 25 years and where the women were 25 or older on marriage. These figures showed a lower 
average number of children among civil servants in the towns (4.1) and the highest average (6.4) among rural estate owners (Johansen 2002). An even earlier analysis, which was based on the census in 1880, also noted fertility differences according to social position, with the highest number of children in families in both the upper and the lower strata of the population, while the smallest families were observed in the middle social strata. In addition, the upper strata had their children later. However, as this analysis only covered Copenhagen, it did not elucidate possible differences due to urbanization (Rubin and Westergaard 1890). In the Census of 1940, the figures revealed smaller families as an effect of the fertility decline (between 1.3 and 2.7 children), but also that this decline had been stronger in the towns and cities, especially in the upper social strata, while the largest families were found in the less urbanised areas of the country (Johansen 2002).

A special investigation of the fertility differences in 1959-1961 (Matthiessen 1965), confirmed that this fertility pattern still existed: For each 5-year age-group the fertility rates within marriage in the capital (Copenhagen) and the boroughs in the metropolitan area were below the national average and lower than in the less urbanized areas. For women in the upper part of the fertile age-span (above 40) the marital fertility rates were 3-5 times as high in the rural municipalities as in Copenhagen. At the beginning of the 1990s, at the end of our study period, the predominant family size was one or two children and the families were still relatively larger in the less urbanised areas than in the big cities (Statistics Denmark 1997). Further, the counties' relative differences regarding fertility patterns that prevailed before the 1960s were still present (Matthiessen 1996).

The studies discussed above revealed the existence of persistent differences in the direction of higher fertility in rural, less urbanised counties. None of these studies took into consideration how long the women in the analyses had lived in the region, which introduces a slight uncertainty when interpreting the fertility differences as resulting from differences in underlying value orientations and preferences regarding fertility and family. In the following we will try to examine the possible underlying dimensions (e.g., value orientations) in the counties more closely, as this might explain the observed differences in first birth rates. For that section of the analysis we will apply the grouping of the counties in Denmark into four regions, as proposed by Tonboe (2001), based on analyses of data sets from the Danish section of the European Value Studies (Gundelach 2002). The four groups were analysed by using data from the three surveys that were conducted in 1981, 1990 and 1999. On the basis of these analyses the regions were categorized as the Capital area, the Urbanised provincial part of the country, the Close periphery and the Distant periphery. It should also be noted, though, that these data are cross-sectional and do not include information about migration between the regions. 
Figure 13: Map of Denmark according to the four groupings suggested by Tonboe (2001)

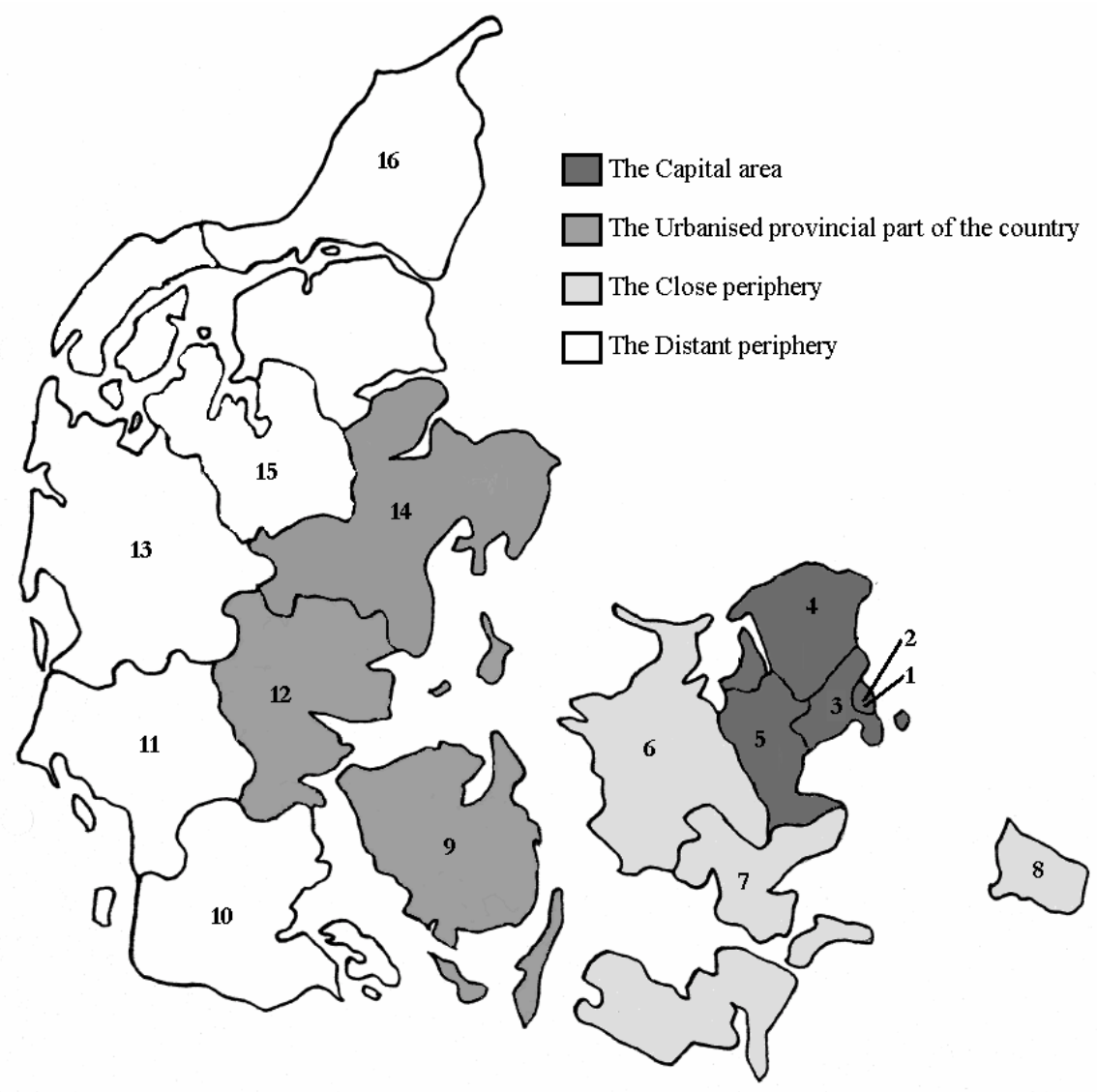

These regions differed from each other in the dimensions of economic-material conditions, including attitudes towards paid work, institutional, social and cultural conditions. One of the sub-dimensions of the social conditions relates to the diversity of family forms. Divorces and living in consensual unions spread to the larger cities all over the country, especially in the Close periphery. Correspondingly, a positive attitude towards the more traditional family form (the nuclear family) in contrast to more modern family values is more widespread in the periphery, that is, in areas in which this form is more common and, also, the number of children in the families is higher in the 
Periphery than in the Capital. In his concluding remarks on the differences and trends in the period 1981-1999, Tonboe remarks that the country has become more homogeneous, - but more in terms of dimensions such as economy, occupational activity and education than in regard to attitudes and values, where there are still important differences. The development regarding modernization, from being more traditional to behaving in a post-modern reflexive way follows a different pace in the four groups of counties, and Tonboe sees the grouping as a fruitful instrument for further theoretical attempts to explain regional characteristics.

As the previous sections of the present analysis demonstrated a good fit of the ageperiod-cohort-interaction model, this model is applied to the grouping suggested by Tonboe, (see Figure 14), which presents the age-specific first birth fertility rates estimated by use of the age-period-cohort-county-interaction model, where county is divided into the four groups suggested by Tonboe.

\section{Figure 14: Estimated age-specific first time fertility rates in age-period-cohort- county, age-county-interaction model according to the groupings suggested by Tonboe (2001)}

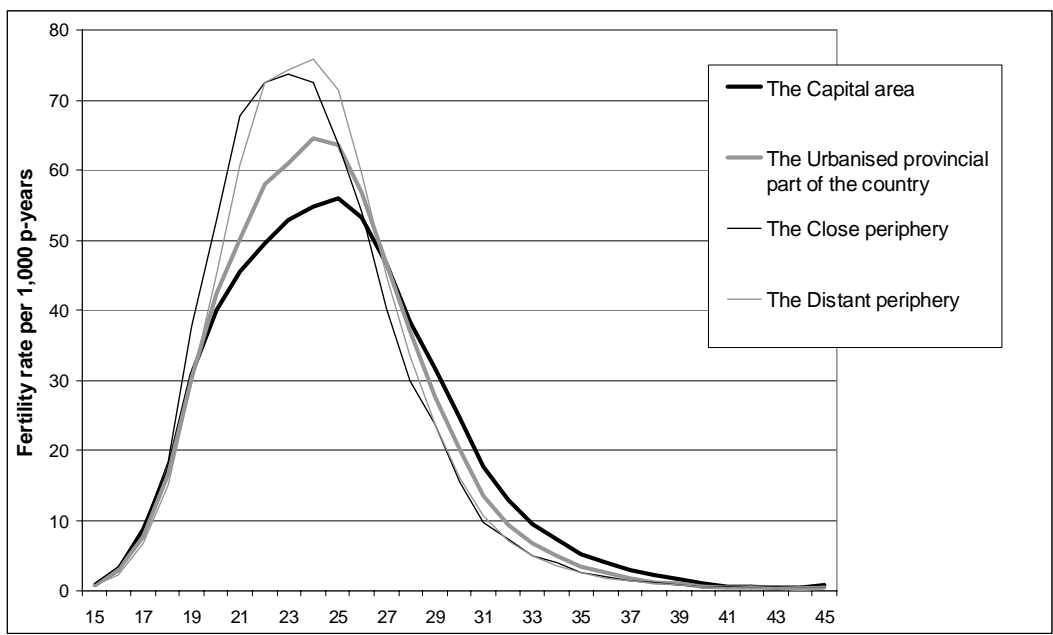

The graph shows that the region classified as the Capital area has the lowest fertility rate for the younger age groups but a higher fertility rate above 28 years of age, while the Close periphery and the Distant periphery have higher fertility rates for women below 25 years of age and have the lowest rates for women above the age of 28 . Thus the age-period-cohort model presents the different age-specific fertility rates 
according to the four regions suggested by Tonboe (2001) standardised for the effect of period and cohort. An examination of the fit of the Tonboe model was performed by comparing observed and estimated rates, which showed a satisfactory fit (not shown). This is further supported by the deviance analysis: $\mathrm{D} / \mathrm{df}=2.0289$.

This examination of the age-period-cohort-county model with an interaction between age and county shows that the model gives a satisfactory description of the regional variation in Denmark for the period 1980 to 1994. The interaction between age and county offers a rather simple formulation of the complex demographic phenomenon of different age-structures of fertility in the regions of Denmark. We also show that the different age-structures of first-time fertility are in accord with the social and cultural groupings proposed by Tonboe (2001). This might offer an explanation for the constant regional differences in fertility observed throughout the whole $20^{\text {th }}$ century (e.g., Pedersen 1988, Statistics Denmark 1992, Statistics Denmark 1997) and support the validity of Tonboe's groupings when fertility is considered.

\section{Conclusion}

In this investigation we analyse the fertility of childless women in the period 19801994. The investigation has been two-phased, analysing both the fertility rate for the whole country and the regional differences between the 14 counties and 2 municipalities in Denmark. The purpose of the investigation was to illustrate how the age-period-cohort model could describe these phenomena and to illustrate how this multiple regression technique could provide knowledge about how the three connected time-scales have influenced the fertility rates.

We show that the age-period-cohort model gives a satisfactory description of the fertility rate of nulliparous women through this 15 year period and we conclude that the model offers an effective standardisation of the effect of age, period and cohort on the fertility rate. This is utilized in the investigation of regional differences of fertility, where a further interaction between age and county gives a concise and effective description of a complicated demographic phenomenon where the age-structure of the fertility rates constantly differs between the counties of Denmark. 


\section{References}

Arbyn M, Van Oyen H, Sartor F, Tibaldi F, Molenberghs G (2002). "Description of the influence of age, period and cohort effects on cervical cancer mortality by loglinear Poisson models (Belgium, 1955-94)." Archives of Public Health, 60: 73-100.

Clayton D, Schifflers E (1987a). "Models for temporal variation in cancer rates. I: Ageperiod and age-cohort models." Statistics in Medicine, 6: 449-467.

Clayton D, Schifflers E (1987b). "Models for temporal variation in cancer rates. II: Age-period-cohort models." Statistics in Medicine, 6: 469-481.

Eurostat/Statistics Denmark (1995). Statistics on persons; a register based statistical system. Copenhagen: Statistics Denmark.

Gauthier AH (1996). The State and the Family. A comparative Analysis of Family Policies in Industrialized Countries. Oxford: Clarendon Press.

Gauthier AH, Hatzius J (1997). "Family benefits and fertility: An Econometric analysis." Population Studies, 51: 295-306.

Gundelach P (ed.) (2002). The Values of the Danes 1981-99. Copenhagen: Hans Reitzel [in Danish].

Hantrais L, Letablier MT (1996). Families and Family Policies in Europe. London and New York: Longman.

Holford TR (1992). "Analysing the temporal effects of age, period and cohort." Statistical methods in medical research, 1: 317-337.

Johansen HC (2002). Danish Population History 1600-1939. Odense: Universitetsforlaget.

Kaufmann FX, Kuijsten A, Schulze HJ and Strohmeier KP(Eds.) (2002). Family Life and Family Policies in Europe. Volume 2. Problems and Issues in comparative Perspective. Oxford: Clarendon Press.

Knudsen LB (1993). Fertility Trends in Denmark in the 1980s. A Register Based Sociodemographic Analysis of Fertility Trends. Copenhagen: Statistics Denmark.

Knudsen LB (1998). "The Danish Fertility Database." Danish Medical Bulletin, 45: 221-225. 
Knudsen LB, Murphy MJ (1999). "Registers as data source in studies of reproductive behaviour." Research Report 12. Odense: Danish Center for Demographic Research.

Knudsen LB (2000). "County wise differences in the trends of induced abortion in Denmark." Ugeskrift for Lager, 162: 2041-2045 [in Danish].

Matthiessen PC (1965). Fertility differences in Denmark. Copenhagen: Det Statistiske Departement [in Danish].

Matthiessen PC (1996). "Regional aspects of reproduction and family formation in Denmark." Nationalфkonomisk Tidsskrift, Suppl 1996: 115-20 [in Danish].

Neyer GR (2003). Family policies and low fertility in Western Europe. MPIDR WP 2003-021. Max Planck Institute for Demographic Research, Rostock.

Pedersen L (1988). Regional fertility differences 1981-1985. Copenhagen: Statistics Denmark [in Danish].

Robertson C, Boyle P (1998a). "Age-period-cohort analysis of chronic disease rates. I: Modelling approach." Statistics in Medicine, 17: 1305-1323.

Robertson C, Boyle P (1998b). "Age-period-cohort models of chronic disease rates. II: Graphical approaches." Statistics in Medicine, 17: 1325-1339.

Rubin M, Westergaard H (1890). Marriage Statistics based on Social Stratification. Kjøbenhavn: Philipsen [in Danish]. German version: Rubin M, Westergaard H (1890). Statistik der Ehen auf Grund der sozialen Gliederung der Bevölkerung. Jena: Fischer.

SAS Institute Inc (1999). SAS/STAT software. Cary, North Carolina: SAS Institute Inc.

Statistics Denmark (1992). Vital Statistics 1990. Copenhagen: Statistics Denmark

Statistics Denmark (1997). The Fertility Development in Denmark from 1980 to 1993 Statistiske efterretninger, Befolkning og valg 1997:3. Copenhagen: Statistics Denmark [in Danish].

Statistics Denmark (2000). Vital Statistics 1999. Copenhagen: Statistics Denmark.

Surkyn J, Lesthaeghe R (2004). "Value Orientations and the Second Demographic Transition (SDT) in Northern, Western and Southern Europe: An Update." Demographic Research, Special Collection 3, art 3: 43-86 (available at www.demographic-research.org/). 
Thygesen, Knudsen \& Keiding: Modelling regional variation of first-time births in Denmark

Tonboe J (2001). "Moral Geography." Sociologisk Arbejdspapir 11. Aalborg: Aalborg University [in Danish]. 